\title{
Should alcohol-based handrub volume be customized according to the size of healthcare workers' hands?
}

\author{
F Bellissimo-Rodrigues ${ }^{1,2^{*}}$, H Soule ${ }^{1,2}$, A Gayet-Ageron ${ }^{1,2}$, Y Martin ${ }^{1}$, D Pittet ${ }^{1,2}$ \\ From 3rd International Conference on Prevention and Infection Control (ICPIC 2015) \\ Geneva, Switzerland. 16-19 June 2015
}

\section{Introduction}

Hand hygiene promotion is the most important tool to prevent health-care associated infections. While hand hygiene compliance has been well studied and promoted for the last 20 years, less attention has been devoted to study the quality of hand hygiene action.

\section{Objectives}

We aimed to evaluate the amount of alcohol-based handrub (ABHR) needed to ensure appropriate hand antisepsis, depending on the healthcare workers ( $\mathrm{HCW})$ hand size.

\section{Methods}

This was an experimental study based on the microbiological laboratory, evaluating 15 healthy HCWs with different hand sizes performing hand hygiene following the World Health Organization (WHO) recommended sequence, with 6 different volumes of 2-propanol $60 \%$ hand rub. According to the European Norm 1500 (EN1500) standard, bacterial count was measured on the HCWs' finger tips at baseline, after one friction without ABHR, then after each application of ABHR from $0.5 \mathrm{~mL}$ to $3 \mathrm{~mL}$. The primary outcome was the $\log _{10}$ reduction measured after each AHBR application. Generalized linear mixed models were performed to analyze the results.

\section{Results}

Among the 15 participants, 10 were female (66.7\%), 4 had small hands, with a mean $( \pm \mathrm{SD})$ hand surface area (HSA) of $332.9 \pm 22.2 \mathrm{~cm}^{2}, 6$ had medium size hands

Infection Control Programme, University of Geneva Hospitals, Switzerland Full list of author information is available at the end of the article (mean HSA $=404.2 \pm 9.7 \mathrm{~cm}^{2}$ ) and 5 had large hands (mean HSA $=473.2 \pm 40.4 \mathrm{~cm}^{2}$ ). The $\log _{10}$ reduction was significantly decreased for each supplemental $0.5 \mathrm{ml}$ of AHBR $\left(0.28 \log _{10}\right.$; $95 \%$ CI: 0.23 to $\left.0.34, \mathrm{p}<0.001\right)$ after adjustment on hand size and baseline $\log _{10}$ count. The $\log _{10}$ reduction was significantly lower for large hands compared to small hands $\left(-1.19 \log _{10}\right.$; $95 \% \mathrm{CI}:-1.61$ to $-0.76, \mathrm{p}<0.001)$, and significantly lower for medium hands compared to small hands $\left(-0.57 \log _{10} ; 95 \% \mathrm{CI}\right.$ : -0.98 to $-0.15, \mathrm{p}=0.007)$. HCWs with large hands achieved a mean reduction of only $1.42 \log _{10} \pm 1.31$, after rubbing their hands with $3 \mathrm{~mL}$ of ABHR.

\section{Conclusion}

These results suggest the need of customizing the volume of ABHR used for hand hygiene, according to the size of the HCWs' hands, for ensure appropriate hand antisepsis and patient safety.

\section{Disclosure of interest}

None declared.

\section{Authors' details}

${ }^{1}$ Infection Control Programme, University of Geneva Hospitals, Switzerland. ${ }^{2}$ Collaborating Centre on Patient Safety, World Health Organization, Geneva, Switzerland.

Published: 16 June 2015

doi:10.1186/2047-2994-4-S1-P302

Cite this article as: Bellissimo-Rodrigues et al: Should alcohol-based handrub volume be customized according to the size of healthcare workers' hands? Antimicrobial Resistance and Infection Control 2015 4(Suppl 1):P302. 